\title{
Tres preguntas fueron útiles para detectar violencia en la pareja
}

Feldhaus K, McLain JK, Amsbury HL. et al. Accuracy of 3 brief screening questions for detecting partner violence in the emergency department. JAMA 1997; 277:1357-61

\section{Objetivo}

Construir y validar un cuestionario para detectar violencia en la pareja.

\section{Diseño}

Administración de encuestas.

\section{Lugar}

Dos salas de guardia de centros urbanos de Colorado, EE.UU.

\section{Pacientes}

Participaron 322 mujeres ( $76 \%$ de las pacientes elegibles) a las que se les realizaron encuestas en forma randomizada. Fueron excluidas pacientes menores de 18 años y aquellos con alteraciones del estado mental.

Descripción del test evaluado y del test de referencia (gold standard)

Toda paciente contestaba en forma confidencial un cuestionario de tres preguntas (Partner Violence Screening (PVS):

1. Alguna vez ha sido víctima de golpes, patadas $u$ otra forma de daño por alguien en el último año ?

2. Ud. se siente segura con su pareja en este momento?

3. Hay alguna persona de una relación previa que la hace sentir insegura ahora?
Posteriormente se les pedía que contestaran dos cuestionarios de referencia (Gold Standard): El Índice de abuso por parte del esposo ((ISA) Index of Spouse abuse) de 30 ítems, también en forma confidencial; y un investigador le formulaba la Escala de tácticas de conflictos ((CTS ) Conflict Tactics Scale ) de 19 ítems.

\section{Medición de resultados}

Se determinó la sensibilidad* y especificidad*; valores predictivos positivo (VPP)* y negativo (VPN)*; y Likelihood ratios positivo $(\mathrm{LR}+)^{*}$ y negativo $(\mathrm{LR})$ * del PVS versus el ISA y el CTS

\section{Resultados}

Sens del PVS Espec. del PVS VPP VPN LR(+) LR(-)

$\begin{array}{lllllll}\text { ISA } & 64.5 & 80.3 & 51.3 & 87.6 & 3.27 & 0.44 \\ \text { CTS } & 71.4 & 84.4 & 63.4 & 88.7 & 4.57 & 0.33\end{array}$

La prevalencia de violencia en este estudio fue de: $29.5 \%$ (IC95\% 24.6-34.8\%)

La primera pregunta fue más sensible y específica que las otras dos.

\section{Conclusiones}

Un breve cuestionario de tres preguntas es capaz detectar muchos casos de violencia de pareja. La primer pregunta de este cuestionario es sumamente sensible, no obstante deben realizarse más investigaciones para rastrear violencia en el ámbito familiar.

\section{*Ver Glosario}

\section{Comentario}

La detección de violencia es una parte importante de la tarea médica y debe realizarse siempre. Este trabajo muestra un buen rendimiento de la sensibilidad del cuestionario que se quiere implementar (64.5\% 71.4\%). Precisamente la sensibilidad es la propiedad más importante ya que se refiere a la capacidad de detectar a las víctimas. La primer pregunta demostró mayor exacti- tud que las otras dos preguntas. No queda claro porqué se excluyó a las pacientes menores de 18 años.

Si bien se encontró un elevado VPP es importante recordar que éste depende de la prevalencia en la población, que en este estudio fue llamativamente alta. Una de las dificultades para usar este cuestionario es compatibilizar la traducción al castella- no de estas tres preguntas (validez externa). De todos modos, este cuestionario resulta de utilidad clínica por su simpleza, no obstante lo cual se requerirán nuevos estudios para perfeccionarlo.

Dr. Alberto Velázquez

Unidad de Medicina Familiar y Preventiva Hospital Italiano de Buenos Aires 